\title{
Is there a relationship between fracture healing and mean platelet volume?
}

\author{
This article was published in the following Dove Press journal: \\ Therapeutics and Clinical Risk Management \\ 13 July 2016 \\ Number of times this article has been viewed
}

\author{
Sancar Serbest ${ }^{1}$ \\ Ugur Tiftikcil \\ Haci Bayram Tosun ${ }^{2}$ \\ Seyit Ali Gumustas ${ }^{2}$ \\ Abuzer Uludag ${ }^{2}$ \\ 'Department of Orthopaedics and \\ Traumatology, Faculty of Medicine, \\ Kırıkkale University, Kırıkkale, \\ ${ }^{2}$ Department of Orthopaedics and \\ Traumatology, Faculty of Medicine, \\ Adiyaman University, Adiyaman, Turkey
}

Correspondence: Sancar Serbest Department of Orthopaedics and Traumatology, Faculty of Medicine, Kırıkkale University, 7I I00 Kırıkkale, Turkey

Tel +905335545080

$\mathrm{Fax}+903182252819$

Email dr.sancarserbest@hotmail.com
Objectives: Platelet volume has been defined to be a marker that shows thrombocyte activation and function and it is measured as mean platelet volume (MPV). MPV shows the mean volume of circulating thrombocytes and it is one of the routine parameters in complete blood count. Increased thrombocyte volume is associated with thrombocyte activation.

Patients and methods: This study included 76 patients who were operated on due to fractures of long tubular bones. Patients who had union without any additional interventions were defined as group I, and patients who needed additional interventions due to nonunion or inadequate union were defined as group II. The control group included healthy volunteers who did not have a fracture. Hematologic test values of the patients that were obtained at admission to emergency ward were recorded.

Results: The groups were not statistically different in terms of age, sex, and the affected extremity. There were significant differences between group I and group II in terms of mean erythrocyte sedimentation rate, $\mathrm{C}$-reactive protein, and MPV values $(P<0.001)$, but there were no significant differences between group I and the control group. There was also no statistically significant difference among groups in terms of hematologic and biochemical variables.

Conclusion: In our study, fractures in patients who had lower MPV values than controls during the inflammation process healed without any problem, but fractures in patients with high MPV values more frequently needed additional surgical interventions.

Keywords: fracture healing, bone tissue, mean platelet volume, platelet activation, inflammation

\section{Introduction}

The process of fracture healing involves interactions among several biomechanical and biological factors. In the US, problems of varying degrees occur in $5 \%-10 \%$ of fractures every year. ${ }^{1}$ Although the cause of this problem is mostly unknown, possible associated factors were reported to be age, nutrition, hormonal status, inadequate reduction, accompanying diseases, infections, drugs, and type of trauma. ${ }^{2}$

Thrombocyte volume has been defined as a marker of thrombocyte activation and function and it is measured as mean platelet volume (MPV). ${ }^{3}$ MPV shows the mean volume of circulating thrombocytes and it is one of the routine parameters in complete blood count. Increased thrombocyte volume is associated with thrombocyte activation. Large thrombocytes include denser granules; they are metabolically and enzymatically more active than smaller thrombocytes and have higher thrombotic potential. ${ }^{4,5}$ MPV has been associated with myocardial infarction, pulmonary embolus, acute pancreatitis, familial Mediterranean fever, diabetic retinopathy, and chronic obstructive pulmonary disease in addition to inflammation, hypoxia, vascular damage, thrombosis, and atherosclerosis. ${ }^{6-11}$ According to Cruess and Dumont, ${ }^{12}$ fracture healing occurs in three phases. The first phase, inflammatory phase, is formed by live tissues and it 
is a very important event that initiates the healing process. Thrombocytes play an important role in the inflammation phase (1-5 days) of fracture healing. ${ }^{13}$ The aim of this study was to investigate whether thrombocyte volume changes affect the fracture healing process, taking into account the functions of thrombocytes in fracture healing.

\section{Patients and methods}

This study included 76 patients who were operated on due to fractures of long tubular bones (tibia, femur) in 2013-2014 and 33 healthy volunteers who were seen in the same period at the orthopedics outpatient clinic. After approval from the Local Ethics Committee of the University of Kirıkkale (IRB number: 25/01), the charts of patients and volunteers included in this study were retrospectively evaluated. Detailed medical, surgical, and trauma (cause of fracture and method of stabilization of fracture) histories, accompanying injuries and history of trauma or fracture of all subjects included in this study were evaluated in the beginning. This study included patients aged between 18 years and 50 years who had closed tibial and femoral diaphyseal fractures treated by intramedullary nail fixation after closed reduction as relative fixation and had no blood transfusion, previous trauma, or fracture history. Patients with open or pathological fracture, osteogenesis imperfecta, rachitism, malignancy, diabetes, chronic renal failure, osteomyelitis, hepatic or hematological disease, and thyroid dysfunction were excluded from the study.

Patients who had union without any additional interventions were defined as group I and patients who needed additional interventions due to nonunion or inadequate union were defined as group II. The control group included healthy volunteers who did not have a fracture or hematologic or endocrinologic pathologies. Hematologic test values of the patients that were obtained at admission to the emergency ward were recorded. Hematologic tests were performed using CELL-DYN Ruby analyzer (Abbott Laboratories, Abbott Park, IL, USA). All biochemical tests were performed using Architect C16000 analyzer (Abbott Laboratories). The radiologic scoring system of Lane and Sandhu was used to evaluate new bone formation at the fracture line. ${ }^{14}$

\section{Patient consent}

We informed both the patient and patient's parents about this study and obtained written informed consent.

\section{Statistical analysis}

All statistical analyses were performed using SPSS Version 16.0 (SPSS Inc., Chicago, IL, USA). Mean, standard deviation, and minimum and maximum values were assessed for the variables. Data were assessed with a $95 \%$ confidence interval. Differences between the three groups were analyzed using the analysis of variance test. The differences were considered significant at $P<0.05$.

\section{Results}

This study included 109 subjects: 76 patients and 33 volunteers. Demographic features of the study groups are presented in Table 1. The groups were not statistically different in terms of age, sex, and the affected extremity. The mean erythrocyte sedimentation rate, C-reactive protein, and MPV values of the groups are given in Tables 2 and 3. There were significant differences between group I and group II in terms of mean erythrocyte sedimentation rate, C-reactive protein, and MPV values $(P<0.001)$, but there was no significant difference between group I and the control group $(P>0.05)$. There was also no statistically significant difference among the groups in terms of hematologic and biochemical variables, such as white blood cells, platelets,

Table I Demographical data of the study group

\begin{tabular}{|c|c|c|c|}
\hline Groups & Group I $(n=43)$ & Group II $(n=33)$ & Control $(n=33)$ \\
\hline Male, $n(\%)$ & $32(74.4)$ & $23(69.7)$ & $14(42.4)$ \\
\hline Female, n (\%) & II (25.6) & $10(30.3)$ & $19(57.6)$ \\
\hline \multicolumn{4}{|c|}{ Age (year), mean \pm SD (range) } \\
\hline Male & $30.94 \pm I 1.24$ & $35.22 \pm 11.68$ & $32.93 \pm 9.82$ \\
\hline Female & $37.55 \pm 11.52$ & $35.20 \pm 7.99$ & $36.89 \pm 10.68$ \\
\hline Total & $32.63 \pm I I .55(18-50)$ & $35.21 \pm 10.57(\mid 8-50)$ & $35.21 \pm 10.36(18-50)$ \\
\hline \multicolumn{4}{|c|}{ Affected extremity } \\
\hline Tibia, n (\%) & $22(51.2)$ & 14 (42.4) & \\
\hline Femur, n (\%) & $21(48.8)$ & $19(57.6)$ & \\
\hline \multicolumn{4}{|l|}{ Side } \\
\hline Right, n (\%) & $21(48.8)$ & $18(54.5)$ & \\
\hline Left, n (\%) & $22(5 \mid .2)$ & $15(45.5)$ & \\
\hline
\end{tabular}

Abbreviation: SD, standard deviation. 
Table 2 Comparison of MPV, ESR, and CRP values of groups and II

\begin{tabular}{llll}
\hline & Group I $(\mathbf{n}=\mathbf{4 3})$ & Group II $(\mathbf{n}=\mathbf{3 3})$ & P-value \\
\hline MPV $(\mathrm{fL})$ & $7.95 \pm 0.90$ & $8.85 \pm 0.87$ & $<0.00 I$ \\
ESR $(\mathrm{mm} / \mathrm{h})$ & $9.44 \pm 5.25$ & $15.91 \pm 8.38$ & $<0.00 I$ \\
CRP $(\mathrm{mg} / \mathrm{dL})$ & $2.02 \pm 1.66$ & $4.25 \pm 2.73$ & $<0.00 \mathrm{I}$ \\
\hline
\end{tabular}

Note: Data shown as mean \pm SD.

Abbreviations: MPV, mean platelet volume; ESR, erythrocyte sedimentation rate; h, hour; CRP, C-reactive protein.

urea, creatinine, hemoglobin, aspartate aminotransferase, and alanine aminotransferase (Table 4).

\section{Discussion}

Among all repair processes within the body, fracture healing is characterized by restructuring, which is the closest to the original tissue without formation of scar tissue. Fracture healing is a complicated process the durability, formation, reproduction, and structuring of which involve many general and local regulators. This process consists of hematoma, inflammation, soft callus, hard callus, and remodeling stages, but still there are many points that need to be exposed. ${ }^{15-18}$ Bone loss results from a disequilibrium between bone resorption and bone formation as well as processes causing high bone turnover. Bone fractures are frequent complications of this imbalance, which result in considerable deficiency and loss of function. ${ }^{19}$ Bone remodeling is a result of the mutual effect between osteoblasts and osteoclasts; an increased bone turnover results from the overactivation of osteoclasts..$^{20}$ Thrombocytes are known to affect both production and degradation phases of bone metabolism. After injury, the site of fracture is surrounded by activated thrombocytes and their aggregates. Then, degranulation of activated thrombocytes causes release of several growth factors such as platelet-derived growth factor (PDGF), vascular endothelial growth factor, insulinlike growth factor-1, insulin-like growth factor-2, epidermal growth factor, and transforming growth factor- $\beta$ (TGF- $\beta$ ). ${ }^{21-23}$ PDGF and TGF- $\beta$, which are released from thrombocytes, have shown effectiveness in osteoblast proliferation and new bone formation. ${ }^{24,25}$ Such growth factors contribute to functioning of osteogenic cells, which is necessary for healing

Table 3 Comparison of MPV, ESR, and CRP values of group I and the control group

\begin{tabular}{llll}
\hline & Group I $(\mathbf{n}=\mathbf{4 3})$ & Control $(\mathbf{n}=\mathbf{3 3})$ & P-value \\
\hline MPV (fL) & $7.95 \pm 0.90$ & $8.26 \pm 0.83$ & 0.276 \\
ESR $(\mathrm{mm} / \mathrm{h})$ & $9.44 \pm 5.25$ & $7.64 \pm 4.18$ & 0.413 \\
CRP $(\mathrm{mg} / \mathrm{dL})$ & $2.02 \pm 1.66$ & $1.83 \pm 1.31$ & 0.913 \\
\hline
\end{tabular}

Note: Data shown as mean \pm SD.

Abbreviations: MPV, mean platelet volume; ESR, erythrocyte sedimentation rate; h, hour; CRP, C-reactive protein. of fractures. ${ }^{21-25}$ The role of thrombocytes in wound healing has been underlined many times previously. ${ }^{26,27}$ Thrombocytes release many growth factors, which play a role in thrombus formation and wound healing, in addition to mediators such as thromboxane A2 and prostaglandin, which are important in both wound healing and bone remodeling. Their effects on bone may be seen during acute (fracture) and chronic (osteoporosis) conditions. ${ }^{13}$ Supporting effects of thrombocytes on bone formation have been reported in both in vitro and clinical studies. ${ }^{26,27}$ Thrombocytes promote bone regeneration by accelerating migration and proliferation of osteogenic cells, ${ }^{17}$ increasing blood vessel formation, ${ }^{18}$ and inducing inflammatory reaction. ${ }^{28}$ Thrombocyte-derived growth factors promote bone formation by affecting cell proliferation, chemotaxis, differentiation, and synthesis of extracellular matrix. ${ }^{29-31}$ Additionally, their protective effect on bone has been demonstrated in clinical studies. ${ }^{32,33}$ Nevins et $\mathrm{al}^{32}$ reported that platelet-rich plasma (PRP) has high amounts of growth factors, and it is positively associated with bone formation. Unfortunately, studies demonstrating increased bone formation by PRP via activation of osteoblasts have remained limited to dental clinical studies and in vitro studies. However, the effects of thrombocytes on osteoclasts have not been highlighted. ${ }^{31-33}$ Ogino et $\mathrm{al}^{34}$ demonstrated inhibitory effects of PRP on osteoclast-like cell formation in the bone marrow. Another study by Ogino et $\mathrm{al}^{35}$ evaluated the effects of PRP on the release of osteoprotegerin (OPG) from the bone marrow cells of rats and found that PRP has a stimulating effect on OPG in the absence of vitamin D3. In contrast with these studies, some authors have demonstrated that PRP inhibits osteoclastogenesis. ${ }^{36} \mathrm{MPV}$ is a parameter of routine complete blood count that is overlooked by many clinicians. Recent advances in clinical laboratory methods have opened new avenues for the understanding of platelets' role in thrombosis, immunity, inflammation, and angiogenesis. ${ }^{37}$ One of the most important effects of thrombocytes is including a series of substances affecting proinflammatory process. These substances are accepted as mediators of inflammatory cells. ${ }^{38}$ Thrombocytes are generally classified within blood cells and undoubtedly play important roles in hemostasis and thrombosis. ${ }^{39}$ Stored thrombocytes play important role in acute inflammatory response and may show direct antimicrobial activity such as neutrophil, granulocyte, and monocyte. ${ }^{40} \mathrm{Li}$ et $\mathrm{al}^{41}$ demonstrated that osteoporotic postmenopausal women had increased MPVs. They also noted that the increase in MPV was accompanied by increased proinflammatory cytokine levels. Cure et $\mathrm{al}^{42}$ demonstrated that a high MPV was associated with fractures, 
Table 4 Laboratory parameters for the three groups

\begin{tabular}{|c|c|c|c|}
\hline & Group I $(n=43)$ & Group II $(n=33)$ & Control $(n=33)$ \\
\hline Hgb (g/dL) & $13.2 \pm 1.9(9.4-17.5)$ & $12.9 \pm 2.1(9.1-16.7)$ & $13.4 \pm \mid .5(|0.1-| 6.3)$ \\
\hline Platelets $\left(\times 10^{9} / L\right)$ & $230 \pm 48(98-307)$ & $237 \pm 57(|37-38|)$ & $253 \pm 48(162-394)$ \\
\hline WBC $\left(\times 10^{9} / \mathrm{L}\right)$ & $9.09 \pm 2.74(4.2-16.6)$ & $8.41 \pm 2.28(3.5-13.8)$ & $7.15 \pm 1.25(5.1-10.5)$ \\
\hline BUN (mg/dL) & $24.6 \pm 10.2(11-57)$ & $26.9 \pm 8.2(10-48)$ & $24.8 \pm 6.7(14-44)$ \\
\hline Creatinine (mg/dL) & $0.93 \pm 0.82(0.4-5)$ & $0.8 I \pm 0.2(0.49-\mid .4)$ & $0.72 \pm 0.13(0.48-0.96)$ \\
\hline AST (IU/L) & $27.72 \pm 20.58(10-146)$ & $28.73 \pm 16.27(14-80)$ & $19.09 \pm 4.1 \mid(13-27)$ \\
\hline ALT (IU/L) & $22.35 \pm 10.72(9-5 I)$ & $27.55 \pm 9.44(\mid I-6 I)$ & $18.52 \pm 6.48(10-38)$ \\
\hline
\end{tabular}

Note: Data shown as mean \pm SD (range).

Abbreviations: Hgb, hemoglobin; WBC, white blood cell; BUN, blood urea nitrogen; AST, aspartate aminotransferase; ALT, alanine aminotransferase.

even in old age. Increased MPV may be related to osteoporosis and an impaired blood supply; consequently, the risk of fracture may be increased. In parallel with these studies, our study also showed high MPV levels to be related to problems in the union of fractures.

The most important limitations of our study are its retrospective nature, small sample size, and inclusion of only long tubular bones.

\section{Conclusion}

Although many studies have been performed about general and local factors that positively or negatively affect fracture stability, fracture detection, and fracture healing, the mechanism of action of these factors has not been totally elucidated yet. There is a great research interest to find factors that positively affect fracture healing and on the best fixation and treatment methods that preserve biological tissue structure. In our study, fractures in patients who had lower MPV values than controls during the inflammation process healed without any problem, but fractures in patients with high MPV values more frequently needed additional surgical interventions. We believe that our study will contribute to the understanding of the pathophysiology of fracture healing and will help future studies about treatment of fractures.

\section{Acknowledgment}

The authors received no financial support for the research and/or authorship of this article.

\section{Disclosure}

The authors report no conflicts of interest in this work.

\section{References}

1. Marsell R, Einhorn TA. The biology of fracture healing. Injury. 2011; 42(6):551-555.

2. Calori GM, Albisetti W, Agus A, Iori S, Tagliabue L. Risk factors contributing to fracture non-unions. Injury. 2007;38(Suppl 2):11-18.

3. Martin JF, Shaw T, Heggie J, Penington DG. Measurement of the density of human platelets and its relationship to volume. Br J Haematol. 1983; 54(3):337-352.
4. Thompson CB, Eaton KA, Princiotta SM, Rushin CA, Valeri CR. Size dependent platelet subpopulations: relationship of platelet volume to ultrastructure, enzymatic activity, and function. Br J Haematol. 1982; 50(3):509-519.

5. Briggs C. Quality counts: new parameters in blood cell counting. Int $J$ Lab Hematol. 2009;31(3):277-297.

6. Şen HS, Abakay Ö, Taylan M, et al. The importance of mean platelet volume in early mortality of pulmonary embolism. J Clin Exp Invest. 2013;4(3):298-301.

7. Pathansali R, Smith N, Bath P. Altered megakaryocyte-platelet haemostatic axis in hypercholesterolaemia. Platelets. 2001;12(5):292-297.

8. Papanas N, Symeonidis G, Maltezos E, et al. Mean platelet volume in patients with type 2 diabetes mellitus. Platelets. 2004;15(8):475-478.

9. Wang RT, Li Y, Zhu XY, Zhang YN. Increased mean platelet volume is associated with arterial stiffness. Platelets. 2011;22(6):447-451.

10. Chu SG, Becker RC, Berger PB, et al. Mean platelet volume as a predictor of cardiovascular risk: a systematic review and meta-analysis. J Thromb Haemost. 2010;8(1):148-156.

11. Sert A, Aypar E, Odabas D. Mean platelet volume in acute rheumatic fever. Platelets. 2013;24(5):378-382.

12. Cruess RL, Dumont J. Fracture healing. Can J Surg. 1975;18(5): 403-413.

13. Sharif PS, Abdollahi M. The role of platelets in bone remodeling. Inflamm Allergy Drug Targets. 2010;9(5):393-399.

14. Lane JM, Sandhu HS. Current approaches to experimental bone grafting. Orthop Clin North Am. 1987;18(2):213-225.

15. Einhorn TA. The science of fracture healing. J Orthop Trauma. 2005; 19(Suppl 10):4-6.

16. Termaat MF, Den Boer FC, Bakker FC, Patka P, Haarman HJ. Bone morphogenetic proteins. Development and clinical efficacy in the treatment of fractures and bone defects. J Bone Joint Surg Am. 2005;87(6): 1367-1378.

17. Giannoudis PV, Einhorn TA, Marsh D. Fracture healing: the diamond concept. Injury. 2007;38(Suppl 4):3-6.

18. Gaston MS, Simpson AH. Inhibition of fracture healing. J Bone Joint Surg Br. 2007;89(12):1553-1560.

19. Salari P, Larijani B, Abdollahi M. Association of hyperhomocysteinemia with osteoporosis: a systematic review. Therapy. 2008;5(2): 215-222.

20. Chrischilles E, Shireman T, Wallace R. Costs and health effects of osteoporotic fractures. Bone. 1994;15(4):377-386.

21. Martineau I, Lacoste E, Gagnon G. Effects of calcium and thrombin on growth factor release from platelet concentrates: kinetics and regulation of endothelial cell proliferation. Biomaterials. 2004;25(18): 4489-4502.

22. Mayr-Wohlfart U, Waltenberger J, Hausser H, et al. Vascular endothelial growth factor stimulates chemotactic migration of primary human osteoblasts. Bone. 2002;30(3):472-477.

23. Kark LR, Karp JM, Davies JE. Platelet releasate increases the proliferation and migration of bone marrow-derived cells cultured under osteogenic conditions. Clin Oral Implants Res. 2006;17(3):321-327.

24. Bolander ME. Regulation of fracture repair by growth factors. Proc Soc Exp Biol Med. 1992;200(2):165-170. 
25. Bostrom MP. Expression of bone morphogenetic proteins in fracture healing. Clin Orthop Relat Res. 1998;355(Suppl):116-123.

26. Sarment DP, Cooke JW, Miller SE, et al. Effect of rhPDGF-BB on bone turnover during periodontal repair. J Clin Periodontol. 2006;33(2): 135-140.

27. Gruber R, Varga F, Fischer MB, Watzek G. Platelets stimulate proliferation of bone cells: involvement of platelet-derived growth factor, microparticles and membranes. Clin Oral Implants Res. 2002;13(5): 529-535.

28. Hofman M, Koopmans G, Kobbe P, et al. Improved fracture healing in patients with concomitant traumatic brain injury: proven or not? Mediators Inflamm. 2015;2015:204842.

29. Lind M, Overgaard S, Glerup H, Søballe K, Bünger C. Transforming growth factor-beta1 adsorbed to tricalciumphosphate coated implants increases peri-implant bone remodeling. Biomaterials. 2001;22(3): 189-193.

30. Wang HL, Pappert TD, Castelli WA, Chiego DJ Jr, Shyr Y, Smith BA. The effect of platelet-derived growth factor on the cellular response of the periodontium: an autoradiographic study on dogs. J Periodontol. 1994;65(5):429-436.

31. Jiang D, Dziak R, Lynch SE, Stephan EB. Modification of an osteoconductive anorganic bovine bone mineral matrix with growth factors. J Periodontol. 1999;70(8):834-839.

32. Nevins M, Camelo M, Nevins ML, Schenk RK, Lynch SE. Periodontal regeneration in humans using recombinant human platelet-derived growth factor-BB (rhPDGF-BB) and allogenic bone. J Periodontol. 2003;74(9):1282-1292.

33. Marx RE, Carlson ER, Eichstaet RM, Schimmele SR, Strauss JE, Georgeff KR. Platelet-rich plasma: growth factor enhancement for bone grafts. Oral Surg Oral Med Oral Pathol Oral Radiol Endod. 1998;85(6): 638-646.
34. Ogino Y, Ayukawa Y, Kukita T, Atsuta I, Koyano K. Platelet-rich plasma suppresses osteoclastogenesis by promoting the secretion of osteoprotegerin. J Periodontal Res. 2009;44(2):217-224.

35. Ogino Y, Ayukawa Y, Kukita T, Koyano K. The contribution of plateletderived growth factor, transforming growth factor-beta1 and insulinlike growth factor-I in platelet-rich plasma (PRP) to the proliferation of osteoblast-like cells. Oral Surg Oral Med Oral Pathol Oral Radiol Endod. 2006;101(6):724-729.

36. Gruber R, Karreth F, Fischer MB, Watzek G. Platelet-released supernatants stimulate formation of osteoclast-like cells through a prostaglandin/ RANKL-dependent mechanism. Bone. 2002;30(5):726-732.

37. Wagner DD, Burger PC. Platelets in inflammation and thrombosis. Arterioscler Thromb Vasc Biol. 2003;23(12):2131-2137.

38. Sprague DL, Elzey BD, Crist SA, Waldschmidt TJ, Jensen RJ, Ratliff TL. Platelet-mediated modulation of adaptive immunity: unique delivery of CD154 signal by platelet-derived membrane vesicles. Blood. 2008;111(10):5028-5036.

39. Semple JW, Freedman J. Platelets and innate immunity. Cell Mol Life Sci. 2010;67(4):499-511.

40. Smyth SS, McEver RP, Weyrich AS, et al. Platelet colloquium participants. Platelet functions beyond hemostasis. J Thromb Haemost. 2009; 7(11):1759-1766.

41. Li XS, Zhang JR, Meng SY, Li Y, Wang RT. Mean platelet volume is negatively associated with bone mineral density in postmenopausal women. J Bone Miner Metab. 2012;30(6):660-665.

42. Cure E, Balik MS, Cumhur Cure M, et al. Is the mean platelet volume predictive of hip fractures in the elderly? Ann Lab Med. 2013;33(5): 367-370.
Therapeutics and Clinical Risk Management

\section{Publish your work in this journal}

Therapeutics and Clinical Risk Management is an international, peerreviewed journal of clinical therapeutics and risk management, focusing on concise rapid reporting of clinical studies in all therapeutic areas, outcomes, safety, and programs for the effective, safe, and sustained use of medicines. This journal is indexed on PubMed Central, CAS,

\section{Dovepress}

EMBase, Scopus and the Elsevier Bibliographic databases. The manuscript management system is completely online and includes a very quick and fair peer-review system, which is all easy to use. Visit http://www.dovepress.com/testimonials.php to read real quotes from published authors.

Submit your manuscript here: http://www.dovepress.com/therapeutics-and-clinical-risk-management-journal 